\title{
NO. 78
}

APRIL 2017

\section{ADB BRIEFS}

\section{KEY POINTS}

- Access to insurance can play a significant role in mitigating risks faced by poor households and micro, small, medium enterprises (MSMEs) by smoothening consumption, building assets, absorbing shocks, and managing risks associated with irregular and unpredictable income. Yet, standard insurance services are out of reach of the millions of the poor and disadvantaged.

- Proper risk management reduces the likelihood that risks will materialize and, if it does, insurance reduces or eliminates the financial impact. Insurance can make MSMEs resilient to shocks, making them more financially sound.

- Tailor-made regulation on insurance products that specifically target SMEs will contribute to increased uptake. For successful uptake of the MSME insurance, it is essential that products offered should add value and are affordable to targeted consumers.

- Since MSMEs inherently face a broad spectrum of risks, many of which are commercially uninsurabl, the development of a special fund to provide financial support for uninsurable risks can enhance the value of insurance and contribute towards MSME industry resilience.
ISBN 978-92-9257-829-9 (Print)

ISBN 978-92-9257-830-5 (e-ISBN)

ISSN 2071-7202 (Print)

ISSN 2218-2675 (e-ISSN)

Publication Stock No. BRF178794-2

DOI: http://dx.doi.org/10.22617/BRF178794-2

\section{INSURANCE FOR MICRO, SMALL, AND MEDIUM-SIZED ENTERPRISES}

\author{
Arup Chatterjee \\ Principal Financial Sector Specialist \\ Sustainable Development and Climate Change Department \\ Asian Development Bank \\ Rodolfo Wehrhahn \\ Consultant \\ Sustainable Development and Climate Change Department \\ Asian Development Bank
}

\section{BACKGROUND}

Small and medium-sized enterprises (SMEs) are a key component of every economy. Studies fill the literature with the importance of SMEs as employment generators, innovators, factors in the supply chains of larger enterprises, and important contributors to gross domestic project.

SMEs are also relevant in developed and developing countries alike, bearing in mind that definitions of SMEs differ by the size of the economy. Estimates suggest that more than $95 \%$ of enterprises around the world are SMEs, accounting for about $60 \%$ of private sector employment.' In the industrialized countries, Japan had the biggest percentage of SMEs, accounting for more than $99 \%$ of total enterprises in $2007 .^{2}$ India had 13 million SMEs in 2008, equivalent to $80 \%$ of the country's businesses. ${ }^{3}$

Estimated data for the 27 countries in the European Union for 2012 (the EU-27 excludes Croatia, which joined in 2013) showed that SMEs accounted for $99.8 \%$ of enterprises and employed $67 \%$ of workers. ${ }^{4}$ They contributed $58 \%$ of gross value

M. Ayyagari, A. Demirgüç-Kunt, and V. Maksimovic. 2011. Small vs. Young Firms Across the World: Contribution to Employment, Job Creation, and Growth. Policy Research Working Paper 5631. Washington, DC: World Bank.

2 Economist Intelligence Unit. 2010. SMEs in Japan: A New Growth Driver? London: Economist Intelligence Unit.

3 S. Ghatak. 2010. Micro, Small and Medium Enterprises (MSMEs) in India: An Appraisal. Paper. http://www.smmeresearch.co.za/SMME\%20Research\%20General/Reports/MSSEs\%20in\%20India .pdf

4 Edinburgh Group Research. 2012. Growing the Global Economy through SMEs. Working paper. http://www.edinburgh-group.org/media/2776/edinburgh_group_research_-_growing_the _global_economy_through_smes.pdf

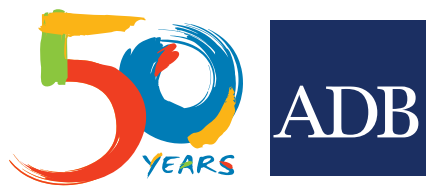


added, defined as value of outputs less value of intermediate consumption, and were an important factor in gross domestic product.

In developing countries, the formal SME sector is competing with a large informal sector. Of the estimated 365-445 million micro, small and medium enterprises (MSMEs) in emerging markets, over $70 \%$ operated informally says a World Bank study. ${ }^{5}$ This number is as high as $90 \%$ in some countries. Moving informal SMEs into the formal economy tops the agenda in countries where informality is high. Improving on the World Bank's "doing business" parameters and providing fiscal incentives is needed to formalize the MSME sector, as are attractive financial sector solutions that support government agendas for gradual reduction of informality.

\section{RISK MANAGEMENT FOR GROWTH AND ACCESS TO FINANCE}

Risk management for resilience and growth among informal MSMEs is weak and highly ineffective. Significant insolvency (with less than $50 \%$ of MSMEs surviving more than 5 years in the European Union) and a significant percentage of nonperforming loans-above $30 \%$ in some countries-also indicate poor risk management. ${ }^{6}$

Not surprisingly, the credit gap is huge, globally estimated at around $\$ 2.5$ trillion. ${ }^{7}$ Access to finance is difficult, costly, and sometimes available only through informal financing mechanisms. Several government initiatives, nongovernment organizations, and multilateral agencies aim to improve MSME access to finance by addressing the enabling environment, financial sector infrastructure development, and through appropriate lending operations and policy work. Essentially, the approach targets improving ability in banks and other financial institutions to assess credit risk and have easily executable collateral.

This brief looks at the important role that better risk management, including insurance, can play in improving access to finance.

\section{RISK MANAGEMENT}

Running an MSME involves strong doses of optimism and, probably, a mindset that ignores most risks to avoid procrastination. Yet, managing risk requires just the oppositethinking about it, assessing its probability, and its possible impact. As such, an MSME owner can hardly carry out effective risk management. This fundamental reality makes MSME risk management poor, unless professional expertise is called upon. However, hiring a risk manager is expensive, and the suggested risk prevention measures will add to costs and, if the risk assessment outpaces the benefits, limit MSME's ability to grow.

In the medium term, proper risk management is highly beneficial. It reduces the likelihood that risks will materialize and, if it does, reduces or eliminates the financial impact. Proper risk management therefore makes MSMEs resilient to shocks, making them more financially sound. Empirical results show that, depending on the quality of the risk management, a higher number of MSMEs survive over the years. ${ }^{8}$ Other benefits include greater ability to deliver on time and improved reliability, enhancing reputation.

That said, while a single averted risk can pay for all risk management activity, as a prepaid operation, risk management value added becomes apparent only in the medium term (in the short term only if an averted risk materializes fast).

The challenge is to make risk management beneficial in the short term as well. Higher creditworthiness of MSMEs with sound risk management systems should be recognized, even for those still lacking proven experience, through cheaper loans and ease of access to those loans. But this is hardly happening. Ideally, lending institutions would explicitly include the quality of the risk management in place in its credit risk assessment. The difficulty is in the ability to carry out that assessment, which traditional lending institutions may not have, while insurers do.

It would therefore appear that insurers are in a better position to quantify the risk reduction effect and accordingly adjust the probability of default and the related credit risk. As such, the participation of insurers in lending activities to MSMEs could help reduce the credit gap. Insurers can assess the quality of risk management systems even before those have proven effective and provide insurance coverage to complement those risk management systems. Either working with traditional lending institutions assessing the quality of the risk management systems or themselves lending to MSMEs insurers could help close the credit gap. ${ }^{9}$ Nonetheless, if allowed to provide credit, insurers should do so cautiously and with sufficient expertise.

5 P. Stein, T. Goland, and R. Schiff. 2010. Two Trillion and Counting: Assessing the Credit Gap for Micro, Small, and Medium-Size Enterprises in the Developing World. McKinsey \& Company and International Finance Corporation. Washington, DC.

6 European Parliament. 2016. Non-Performing Loans in the Banking Union: Stocktaking and Challenges. Briefing. Directorate-General for Internal Policies Economic Governance Support UNI, European Parliament. Brussels.

7 P. Stein, O. P. Ardic, M. Hommes. 2013. Closing the Credit Gap for Formal and Informal Micro, Small, and Medium Enterprises. Washington, DC: International Finance Corporation.

8 E. Falkner and M. Hiebl. 2015. Risk Management in SMEs: A Systematic Review of Available Evidence. The Journal of Risk Finance. 16 (2). pp. $122-144$

9 In the Netherlands, a group of nine insurance companies is extending credit to small and medium-sized businesses through ABN AMRO. The parties involved are presenting a new partnership, linking the investment capital available at insurance companies to the demand for credit among SMEs. ABN AMRO plays an intermediary role by arranging the credit facilities and managing risks. 


\section{INSURANCE FOR THE MSME SECTOR}

\section{Adapting Regulation to MSME Insurance}

Falling between individuals and corporations, MSMEs are often neglected in financial regulation. Recently, special regulation has been developed to improve access to insurance for low-income people, but little effort has been made in insurance for MSMEs. This might be because MSME insurance is often seen as just traditional insurance.

Nonetheless, some MSME needs call for insurance products that cannot be offered under most existing insurance regulations. For instance, it might be necessary to allow distribution channels to provide advice, something that is currently not permitted. The premium payment pattern might need to be adjusted to the economic cycle of MSMEs, which could be contrary to current regulatory requirements on maintaining the validity of coverage. The types of benefits that insurance firms could provide-and that might not be covered by current regulation-range from assistance, consultancy, advice, relocation of machinery, and raw materials, replacement of damaged machinery and goods unemployment insurance, and credit measures by providing loans through banks.

Finally, consumer protection regulations are usually tailor-made to protect individuals and not enterprises. Standing somewhere between individual and enterprise as they do, consumer protection rules may require revisions to reflect the specifics of MSMEs.

In contrast to the need for risk transfer in tailor-made insurance products for MSMEs, which might be small given the potentially small amounts insured, the need for knowledge transfer and financing are big. As such, international reinsurers who are important players should be involved when the market is innovating insurance products. MSME insurance regulation should be developed to encourage insurers to design tailor-made insurance solutions for MSMEs.

As noted, because SME risk profiles strongly commingle individual and business risk, they require innovative insurance products and conducive regulation should incentivize the innovation to meet the need. Regulation could allow for experimenting with products, reduce regulatory costs, use of digital technology applications, yet require detailed analysis of the targeted market as part of product development.

Tailor-made regulation on insurance products that specifically target MSMEs will enhance uptake.

\section{Addressing Uninsurable Risks First}

MSMEs inherently face a wide spectrum of risks, many of which are commercially uninsurable. For instance, terrorism, floods in flood-prone zones, property in landslide-exposed areas, or pandemics, riots, strikes, energy blackouts, or any external force- majeure that can limit business. Insurance therefore cannot cover some of the risks MSMEs face. A firm may remain vulnerable to shock and end up facing severe risk, even after purchasing insurance, because of these uninsurable risks in insurance policies and credibility of insurance would suffer.

The development of a special fund to provide financial support for uninsurable risks would therefore enhance the value of insurance. Complementing the uninsurable risks with financial programs for those risks would boost insurance use and MSME industry resilience.

\section{Educating without Penalizing}

Notwithstanding major efforts from governments, nongovernment organizations, and donors to improve insurance literacy, surveys show that proper understanding of insurance products remains extremely low among MSMEs. And policyholders making claims which are not admissible may carry an erroneous perception that they have been misled. This misunderstanding can hinder insurance sector development and increasing acceptance by the population. Yet, insurers cannot allow uncovered claims to be paid out, as this would affect pricing and other policyholders not affected by the claim.

A fund that preserves the image of insurance without penalizing new insurance consumers is critical. Such a fund should allow settlement of claims outside the strict interpretation of policy wording for affected policyholders that have genuinely misunderstood the coverage or whose claims fall on the borderline of exclusion. Such a fund would defend the image of insurance without compromising the legality of products or their technical pricing without penalizing policyholders for inadequate understanding of insurance products.

The fund would also collect data on exclusions or policy wording causing difficulty in understanding or acceptance. This information should be used to target education, disclosure, or removal of exclusions or policy wording with the proper price adjustment of the product.

\section{The Right Products}

With few exceptions, insurers have not sufficiently targeted the MSME sector as clients. Only the standard insurance products are usually offered, and no tailor-made products targeting the specific needs of the MSMEs have been developed. A thorough understanding of the value chain of different MSMEs and innovative thinking is necessary to develop appropriate products. Successful products that address MSME sector needs have at least the following features:

(i) They are based on a detailed analysis of the business model of the targeted MSMEs that consider the following issues:

- $\quad$ value chain processes and their inherent risks;

- $\quad$ risks selected that the insurance product intends to protect; 
- $\quad$ risks that will be or are covered by other schemes, such as government programs, structured financing, and risk management techniques; and

- uncovered risks.

(ii) Product characteristics take into consideration:

- costs at an affordable level in accordance with targeted consumers;

- $\quad$ accessible and trusted distribution channels;

- premium payment patterns that reflect the economics of the targeted consumers;

- complaints handling that is readily available and accessible in location, media, and language to the targeted consumers;

- claims settlement timeframe that guarantees the effectiveness of the benefit, avoiding the need for temporary high cost credits;

- renewals that are simple and that reflect possible changes in the risk profile; and

- religious and cultural preferences.

(iii) Traditional MSME protection products, such as business interruption, partner insurance, and key man insurancewith riders covering re-education expenses, business transition costs, and entrepreneurial advice-should be available at affordable prices.

(iv) The design of insurance products that address the special needs of MSMEs after a catastrophic event should be encouraged. Certain products that help maintain income, such as business interruption, re-educational benefits, and access to loans in case of catastrophic events, should be stimulated. If mandatory coverage is required for MSMEs, those products should be included.

\section{Lowering Insurance Costs}

For successful uptake of the MSME insurance, it is essential that products offered should add value and are affordable to targeted consumers. The high distribution cost of insurance products needs to be addressed. Any cost reduction should not be a detriment to coverage or service quality. The proposed measures should consider the following:

(i) The design of products should target sufficient potential business volume. If needed, government or donor intervention might be required to achieve critical business volume in the first years.

(ii) The concept of indemnity of a lesser value of the actual loss should be present to avoid incentives that motivate fraud.

(iii) Avoid add-ons or marketing gimmicks that add excessively to costs without commensurate benefits for the consumer.

(iv) Allowing insurers to carefully provide loans to MSMEs can create important synergies, lowering distribution costs and creating additional income.

\section{Addressing the Cost Associated with Lack of Statistics and Pricing Data}

Whenever actuaries and insurance professionals price a product, the expected claims experience is an important factor. The central technique for assessing future claims experience is based on data from past claims. Unfortunately, such data or statistics in countries with low insurance penetration is not readily available. In such cases, insurers add a margin to the price that should protect them from possibly underestimating the future claims experience. Another technique to price products is to use rates from reinsurers' that have wide experience, but the reinsurers' involvement will add to the costs to the product. Ultimately, the consumer bears the additional cost on insurance due to limited data.

Introducing a mechanism that avoids additional insurance costs associated with a lack of data, pricing statistics, and claims experience that is transferred to MSME consumers as conservative pricing will help develop proper risk management by increasing the protection MSMEs will be able to purchase.

The establishment of an experience pricing fund appears to offer one interesting solution. The experience pricing fund, acting as a reinsurer, will cover deviation of fair pricing, allowing insurers to price products for MSMEs without adding surcharges for lack of credible pricing data. The experience pricing fund at the same time will gather claims statistics to allow for more accurate technical pricing without its direct intervention. Aggregated statistics thus developed would serve as a common benefit for the development of MSMEs insurance with fair pricing.

\section{CONCLUSIONS AND RECOMMENDATIONS}

Supporting MSME sector development is essential to employment and economic growth. As such, reducing the credit gap and improving access to finance are crucial, especially credit for MSMEs. In addition to initiatives targeting availability of executable collateral and credit risk assessment, the improvement of MSME risk management systems is important.

MSMEs with prime risk management systems in place, even in the early stages of their existence, should be able to benefit from cheaper financing. Risk management experts, which includes insurers, are ideal candidates to properly assess existing risk management systems and help in better pricing of credit risk. In addition, allowing insurers to provide credit to MSMEs would create competition and open avenues for greater supply of credit, thereby helping narrow the credit gap.

The creation of the following three funds where technical assistance and financing to support development of MSME risk management systems and insurance is needed: 
(i) The development of a special fund to provide financial support for uninsurable risks will enhance the value of insurance to assist businesses to recover from uninsurable events.

(ii) The introduction of a fund that preserves the image of insurance without penalizing new insurance consumers and gathering information that allows targeted educational programs or design of better products by removing certain misleading exclusions.

(iii) The establishment of an experience pricing fund that, acting as a reinsurer, will cover deviation of fair pricing, allowing insurers to price products for MSMEs without adding surcharges for lack of credible pricing data.

About the Asian Development Bank ADB's vision is an Asia and Pacific region free of poverty. Its mission is to help its developing member countries reduce poverty and improve the quality of life of their people. Despite the region's many successes, it remains home to a large share of the world's poor. ADB is committed to reducing poverty through inclusive economic growth, environmentally sustainable growth, and regional integration.

Based in Manila, ADB is owned by 67 members, including 48 from the region. Its main instruments for helping its developing member countries are policy dialogue, loans, equity investments, guarantees, grants, and technical assistance.
The views expressed in this publication are those of the authors and do not necessarily reflect the views and policies of ADB or its Board of Governors or the governments they represent.

Asian Development Bank

6 ADB Avenue, Mandaluyong City

1550 Metro Manila, Philippines

Tel +6326324444

Fax +6326362444

www.adb.org/publications/series/adb-briefs

ADB Briefs are based on papers or notes prepared by ADB staff and their resource persons. The series is designed to provide concise, nontechnical accounts of policy issues of topical interest, with a view to facilitating informed debate. The Department of External Relations administers the series.

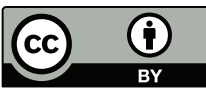

Creative Commons Attribution 3.0 IGO license (CC BY 3.0 IGO)

(C) 2017 ADB. The CC license does not apply to non-ADB copyright materials in this publication. https://www.adb.org/terms-use\#openaccess http://www.adb.org/publications/corrigenda

pubsmarketing@adb.org 